\title{
Editorial
}

\section{Connections with Clive}

I SHARED some memories of Clive and paid my personal tribute in NTQ 83, the issue that immediately followed his death; so in this brief introduction to our special issue celebrating his life and work I want rather to look at the contributions we have included, and how these connect with Clive's legacy.

This is only the second special issue NTQ has published. The first, back in 1994, was to celebrate the eightieth birthday of Jan Kott; and it is a mark of the journal's eclecticism that two such different personalities should have been among its stalwarts. Though he was happy to make an exception for Jan, Clive was against publishing special issues, precisely because he felt (as do I and Clive's successor in the co-editorial chair, Maria Shevtsova) that it is better to find serendipitous connections in diversity than to labour mightily over a single theme. But while we still put together issues in the hope of achieving a balance of contrasting ideas, themes, and kinds of writer, nonetheless I am often struck by the connections that remain to be found - the inner dialogues within diversity that Eugenio Barba, in the tribute that follows, engagingly likens to counterpoint.

Such a dialogue is to be found here between Eugenio's and Dick McCaw's views on improvisation and its role in Clive's work for the issue would not have been complete without the full (not uncritical but always respectful) critiques of Clive's Theatre Games which both Dick and (from a very different angle) Chrissie Poulter provide. Chrissie is a former student of Clive's, and Lizbeth Goodman a protégée the value of whose work Clive recognized early on; he was not the most computer-literate of souls, but Lizbeth persuaded him of the potential for those with disabilities of combining virtual and actual worlds. Although by then he was suffering the effects of his first stroke, Clive disregarded his own disability in his determination to assist those who were also resolved to live apparently restricted lives to the full. He had been conducting a workshop for children with cerebral palsy on the day he died, and time would surely have found him wholeheartedy involved in the project that Lizbeth and Chrissie continue to pursue, and which they document in this issue.

My own contribution is perhaps a little self-indulgent, in that it has allowed me to conduct in public one of those internal debates I regularly have with contributions as I read and re-read them while they make their way to press. Clive had been encouraging Mary Brewer to commit her thoughts on Peter Pan to paper when along came Anne Varty's article taking a quite different approach to the same play - both equally viable, but in their differences suggesting to me all sorts of connections and tangents which I have allowed myself to pursue. This is not so much a scholarly article (dammit, not a footnote in sight), more a tidied-up stream-ofconsciousness such as (I would like to think) articles in NTQ ideally germinate. I used to drift gently down such streams of consciousness with Clive, and suspect I can hear him splashing along his own tributary on high.

Other contributions need less in the way of editorial gloss. Four relate to various aspects of Theatre Workshop and its director, Joan Littlewood, with whom Clive enjoyed a lifelong relationship which mingled admiration and doubts. And Juliusz Tyska writes of Theatre of the Eighth Day, whose forty-year history coincided with Clive's long-standing commitment to often embattled colleagues in Poland and elsewhere in Eastern Europe.

In fact, although this is one of our rare 'special issues', in many ways it is as eclectic as most, reflecting as it does the wide range of Clive's own interests and the variety of people whose lives he touched.

SIMON TRUSSLER 